\title{
Bilateral atrial appendage aneurysms associated with atrial fibrillation.
}

\section{$\operatorname{AUTHOR}(\mathrm{S}):$}

Nakahara, Takahiro; Minakata, Kenji; Yamazaki, Kazuhiro; Funamoto, Masaki; Sakata, Ryuzo

\section{CITATION:}

Nakahara, Takahiro ...[et al]. Bilateral atrial appendage aneurysms associated with atrial fibrillation.. Asian cardiovascular \& thoracic annals 2014, 22(3): 347-349

\section{ISSUE DATE:}

2014-03

URL:

http://hdl.handle.net/2433/185181

\section{RIGHT:}

(C) The Author(s) 2013; Reprints and permissions: sagepub.co.uk/journalsPermissions.nav; この論文は出版社版でありません。引用の際には出版社版をご確認ご利用ください。; This is not the published version. Please cite only the published version. 
++ Surgical treatment of bilateral atrial appendage aneurysms associated with atrial fibrillation

Running Head: Resection of atrial appendage aneurysms

Takahiro Nakahara, MD

Kenji Minakata, MD, $\mathrm{PhD}$

Kazuhiro Yamazaki, MD, PhD

Masaki Funamoto, MD

Akira Marui, MD, PhD

Ryuzo Sakata, MD, PhD

Department of Cardiovascular Surgery

Kyoto University Graduate School of Medicine, Kyoto, Japan

Total word count: 1,123

Total number of Figures: 3

Corresponding author: Kenji Minakata, MD

Mailing address: 54 Kawaharacho, Shogoin, Sakyo-ku, Kyoto, Japan 606-8507

Tel: +81-75-751-3780

Fax: $+81-75-751-3098$

Email:minakata@kuhp.kyoto-u.ac.jp 


\section{ABSTRACT}

Aneurysm of the left atrial appendage (LAA) is an extremely rare anomaly. Herein, we report on the case of 68-year-old man, who presented with palpitation. He was found to have a very large aneurysm located near the LAA by routine echocardiography. During surgery, he was found to have a small aneurysm of the right atrial appendage (RAA) in addition to the LAA aneurysm. We successfully performed resection of both atrial aneurysms in addition to mitral annuloplasty and a Maze procedure. To the best of our knowledge, this is the first surgical case with bilateral atrial appendage aneurysms in the literature.

\section{CASE REPORT}

A 68-year-old man was admitted to our institution for treatment of atrial arrhythmias. He had first presented with paroxismal supraventricular tachycardia four years earlier and was treated with antiarrhythmic agents. Despite the pharmacological treatment, he developed atrial fibrillation and was anticoagulated with warfarin one year prior to the present intervention. On presentation, he complained of frequent episodes of palpitation, and his electrocardiogram (ECG) showed atrial fibrillation with a slightly rapid ventricular response (101 beats per minute) at rest. His chest X-ray showed no apparent abnormalities. Transthoracic echocardiography revealed a large cystic mass connected to the left atrium next to the LAA. It also revealed moderate MR with a mildly enlarged left atrium. His left ventricular ejection fraction was preserved at 70\%. Multi-slice 3D-CT revealed a very large aneurysm arising from just caudal to the LAA, anteriorly to the left pulmonary veins (Figure 1). The size of the aneurysm was $44 \mathrm{~mm}$ (width) x 43mm (depth) x $51 \mathrm{~mm}$ (height). Surgery was then planned.

We gained surgical access to the aneurysm by median sternotomy. The pericardium was intact and free of adhesions. Soon after entering the pericardial space, the large LAA aneurysm was easily identified and a similar, but smaller, aneurysm was found on the RAA (Figure 2). Because of its relatively small size, it had not been detecting on imagining. Under standard cardiopulmonary 
bypass and cardioplegic arrest, the left atrial aneurysm was excised completely at the origin from the left atrium, then closed with 4-0 monofilament suture in double layers. There was no thrombus formation inside the aneurysm. After this, we performed a Cox-Maze IV procedure using a radiofrequency device and cryoablation, and mitral annuloplasty was performed using a posterior annuloplasty band. The RAA aneurysm was also excised during the Maze procedure. The patient's postoperative course was uneventful, except for the fact that he required permanent pacemaker implantation due to pre-existing sick sinus syndrome. Postoperative CT showed complete resection of the LAA aneurysm. Pathological study of both aneurysm specimens revealed extremely thin walls with no muscular structures (Figure 3). Microscopic examination demonstrated cystic lesions with hypertrophic myocardium and fibrosis on the both aneurysms. At three months post-surgery, the patient was doing well with no cardiac symptoms and normal sinus rhythm on ECG.

\section{DISCUSSION}

Aneurysmal dilatation of the left atrium can have either acquired or congenital etiology ${ }^{1-2)}$. Severe mitral stenosis or regurgitation can often cause extreme atrial dilatation as a result of pressure and/or volume overload. However, it is easy to discriminate between atrial dilation and a true LAA aneurysm of the type found in the present case based on morphological findings. LAA aneurysms usually arise from or adjacent to the LAA without severe dilatation of the body of the left atrium itself $^{3-4)}$. In fact, atrial appendage aneurysms are thought to result from congenital dysplasia of musculi pectinati. Atrial appendage aneurysms are mostly located near the LAA, although they have also been found on the wall of the left atrium and, rarely, on the right atrium.

LAA aneurysms do not usually cause any clinical symptoms until the second or third decade of life ${ }^{1-4)}$. Common symptoms include palpitation, dyspnea, or neurological deficits due to embolic stroke. Diagnosis of LAA aneurysm is easily made with echocardiography, chest CT or MRI. Transesophageal echocardiography is also very useful for detecting thrombus formation in the aneurysm. 
Once a diagnosis is made, surgical resection is always recommended even in asymptomatic patients because of the risk of severe complications such as rupture, embolization, atrial arrhythmia, and congestive heart failure. Although a minimally invasive left thoracotomy can be performed to resect a LAA aneurysm without cardiopulmonary bypass, we think that complete resection under cardioplegic arrest is much safer because the aneurysm walls are usually very thin and fragile. Also, clamping the neck of the aneurysm poses the risk of incomplete resection of the aneurysm. Furthermore, because atrial fibrillation or tachyarrhythmia is very common on presentation of this condition, a concomitant Maze procedure can be useful for treating the arrhythmia, although some authors have reported than normal sinus rhythm spontaneously returned in patients in whom the aneurysm was resected without ablation to treat the arrhythmia ${ }^{3,6)}$.

Our meticulous review of the literature failed to identify a case of bilateral atrial appendage aneurysms like the one reported on here. Although there have been several reports of aneurysms of the $\mathrm{RAA}^{7)}$, this is the first report of a case in which bilateral atrial appendage aneurysms were surgically resected at the same time.

\section{REFERENCES}

1. Gold JP, Afifi HY, Ko W, Horner N, Harn R. Congenital giant aneurysm of the left atrial appendage: diagnosis and management. J Cardiac Surg 1996;11:147-50

2. Kruger SK, Felic RM, Mooring PK. Left atrial appendage aneurysm: correlation of noninvasive with clinical and surgical findings: report of a case. Circulation 1975; 52:732-8

3. Mathur A, Zehr KJ, Sinak LJ, Rea RF. Left atrial appendage aneurysm. Ann Thorac Surg 2005; 79:1392-34

4. Fuente A, Urchaga A, Sanchez R, Fernandez JL, Moriones I. Congenital aneurysm of the left atrial appendage. Ann Thorac Surg 2008;85:2139-40

5. Kawata M, Imanaka K, Matsuoka T, Yamabi H. Left atrial appendage aneurysm causes severe mitral regurgitation and heart failure: Report of a successfully treated case. J Thorac Cardiovasc 
Surg 2012;143:e17-8

6. Nagai T, Higaki J, Okayama H. Atrial tachycardia in congenital left atrial appendage aneurysm: three-dimensional computed tomography imaging with electro-anatomical mapping. Eur Heart J 2010

7. Gulati A, Gheta R, Chan CF, et al. Longitudinal follow-up of a right atrial appendage aneurysm by cardiac magnetic resonance imaging. Circulation 2011;123:2289-91

\section{DISCLOSURE:}

We received no financial support and none of the authors had any conflicts on interest in regard to this report.

\section{FIGURE LEGENDS}

Figure 1. 3D-CT showed a very large aneurysm arising from left atrium near the left atrial appendage (LAA): a lateral view (left) and a posterior view (right).

Figure 2. Intraoperative photographs revealed a small RAA aneurysm (left) and a very large LAA aneurysm (right).

Figure 3. The pathological specimens had similar findings on both atrial aneurysms (the RAA aneurysm on the left, the LAA aneurysm on the right): aneurysm formations with very thin walls adjacent to the trabecular portion of the LAA or the RAA. 
Figure 1.
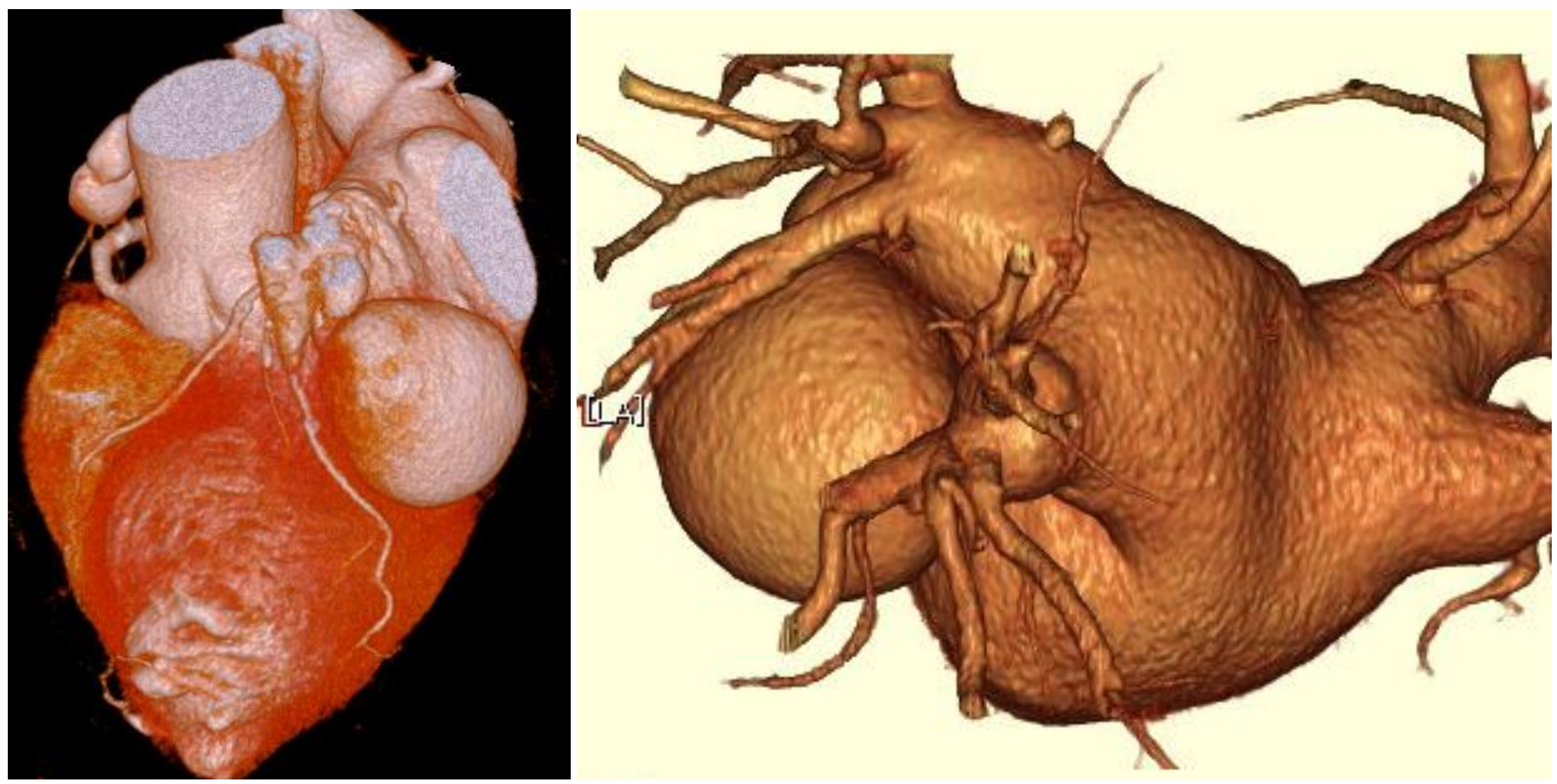
Figure 2.
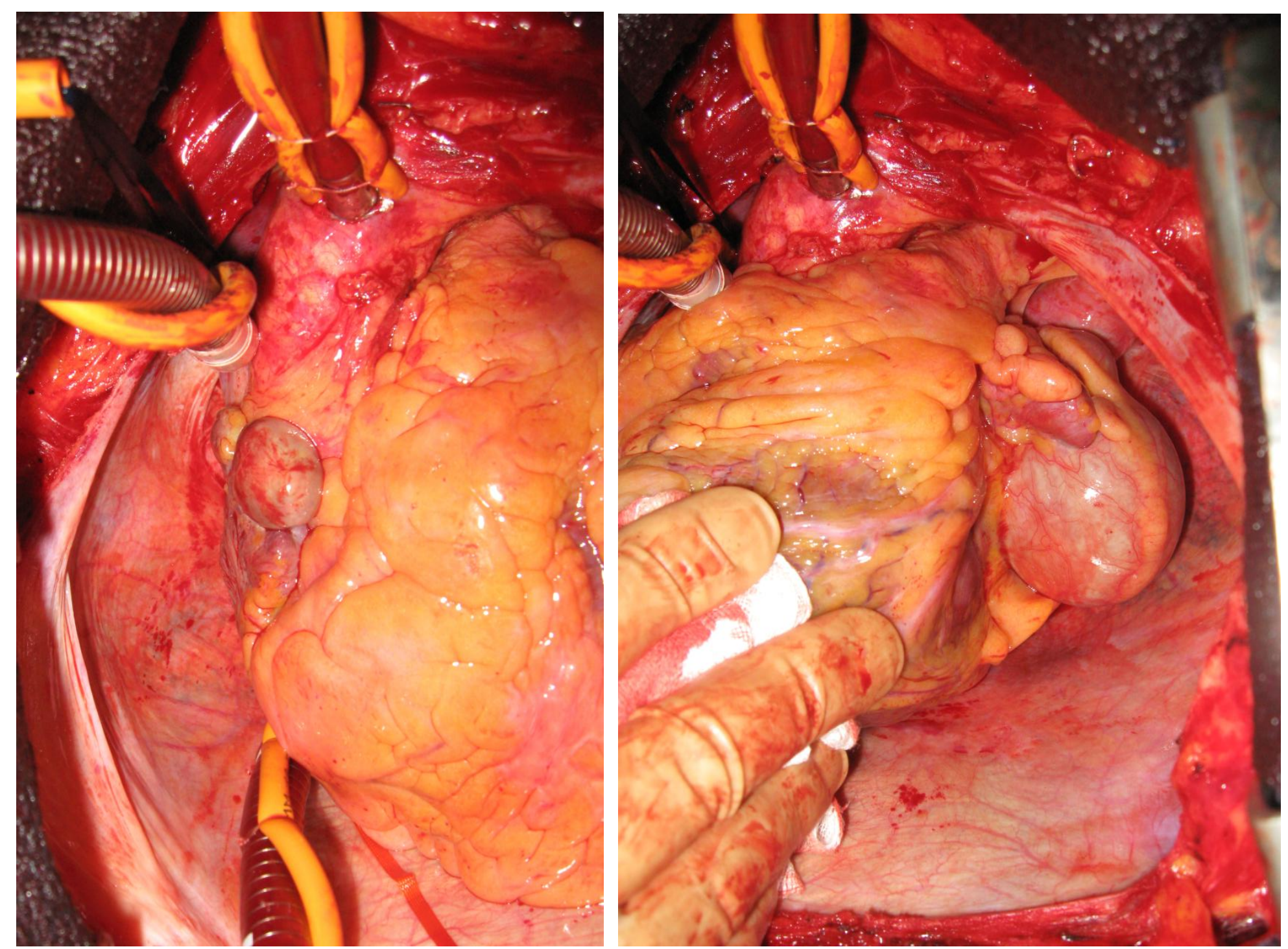


\section{Figure 3.}

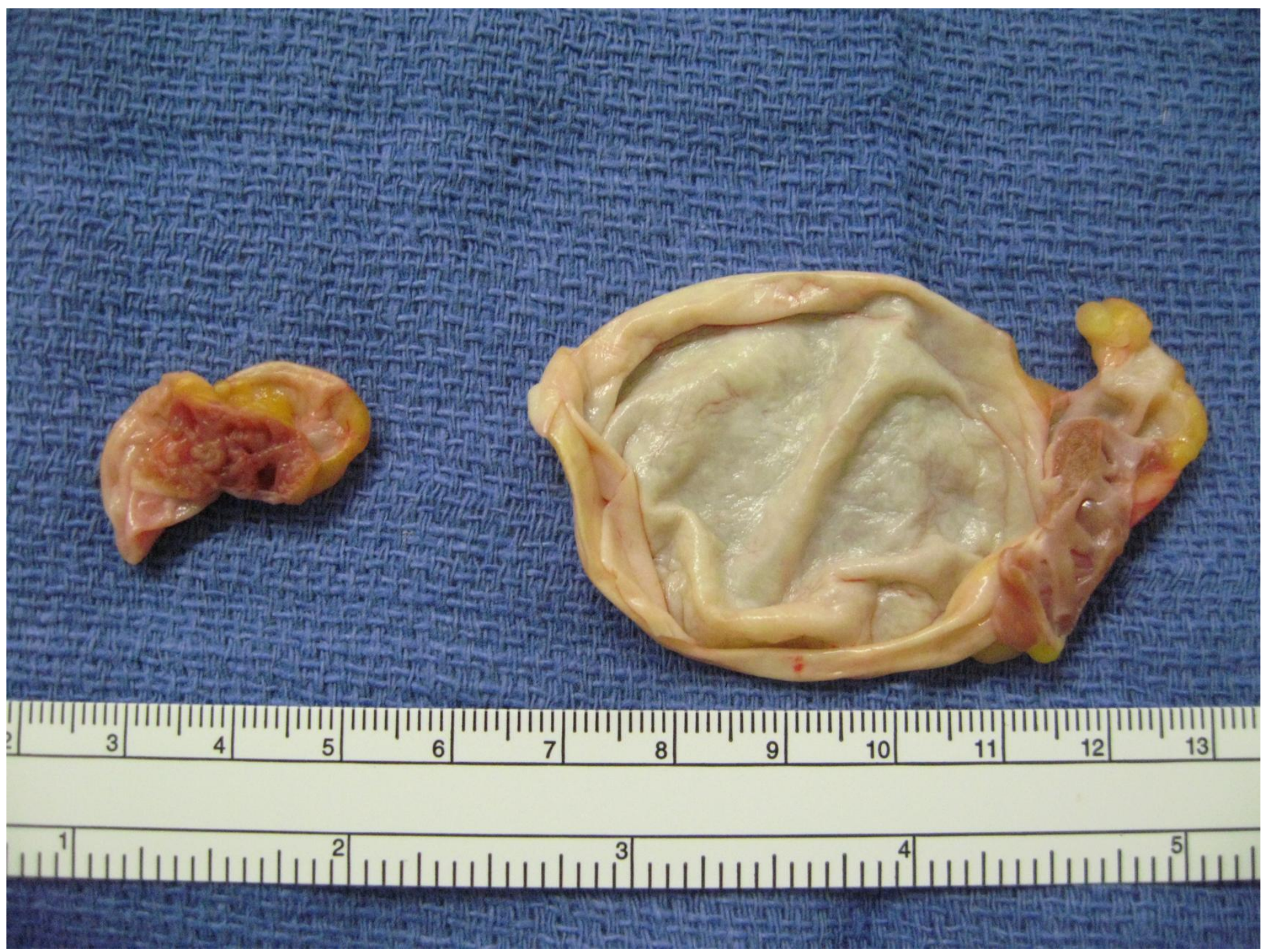

